\title{
Delegation Process of Virtual Countries: From Non-State Actors To State Actors*
}

\author{
Youn Jung Park**
}

\begin{abstract}
The identity of each nation on the Internet is represented through country code top-level domain names (ccTLDs). This article uses regime theory to describe the process of delegating ccTLDs, also known as virtual countries. Initially, non-state actors appointed by the emperor of virtual countries, Jon Postel, administered the virtual countries. There was no challenge from state actors until the ICANN regime was created by the US government in 1998. Unlike other international regime, the ICANN 'regime' recognizes non-state actors as decisionmakers while state actors as advisors for the virtual countries in their decisionmaking process. This has often led to conflicts within the national regime of many virtual countries. This study found that more and more state actors have expressed their willingness and interests in administering their virtual countries. Governments have started to emerge as a threatening power to the non-state actors of the virtual regime as a competitive power in managing the virtual countries.
\end{abstract}

Keywords: Delegation, ccTLDs, State Actors, Non-State Actors, ICANN Regime

* This article was developed out of her dissertation, Political Economy of Virtual Countries. Political Economy of Virtual Countries presents 35 ccTLDs of OECD including EU and BRIC countries. The author would like to appreciate three anonymous reviewers for their perceptive comments in completing this final version and extend her thanks to Jisuk Woo for her recognition of this research area and her guidance in preparing the paper, and Professor Milton Mueller for his useful comments on the piece. The author alone takes responsibility for the contents.

** Youn Jung Park is a doctoral candidate at School of Information Studies, Syracuse University. Her dissertation is planned to be defended in spring 2008. Her research interests include multilingual Internet names, country code top level domains, UN Internet Governance Forum, role of government and civil society in the global decision-making process and governance issues of online gaming including item trade in virtual community. Email: yjpark@syr.edu.

Manuscript received February 2008; out for review February 2008; review completed February 2008; accepted February 2008.

The Korean Journal of Policy Studies, Vol. 22, No. 2, $25-59$ (2008)

(C) 2008 by the GSPA, Seoul National University 


\section{INTRODUCTION}

This study looked into how country code top level domains (ccTLDs) were delegated from 1985 to 2007. The delegation process of ccTLDs can be divided into two different stages: Jon Postel's legacy delegation stage and the Internet Corporation for Assigned Names and Numbers' (ICANN) legacy delegation stage. As of 2007, the first stage, Jon Postel's legacy delegation process, which lasted from 1985 to 1998, was neither publicly recorded nor academically studied. In this period, non-state actors were appointed by Jon Postel to administer ccTLDs as part of a research project. In the present study, the term non-state actors refers to this technical community, which is often categorized either as part of the private sector or having independent status as a technical community. ${ }^{1}$ As we can see in the figure 1, 240 ccTLDs were delegated to non-state actors during the Postel's era. This article reconstructed how non-state actors

Figure 1. Delegation of 240 Country Code Top Level Domain Names by the Technical Community

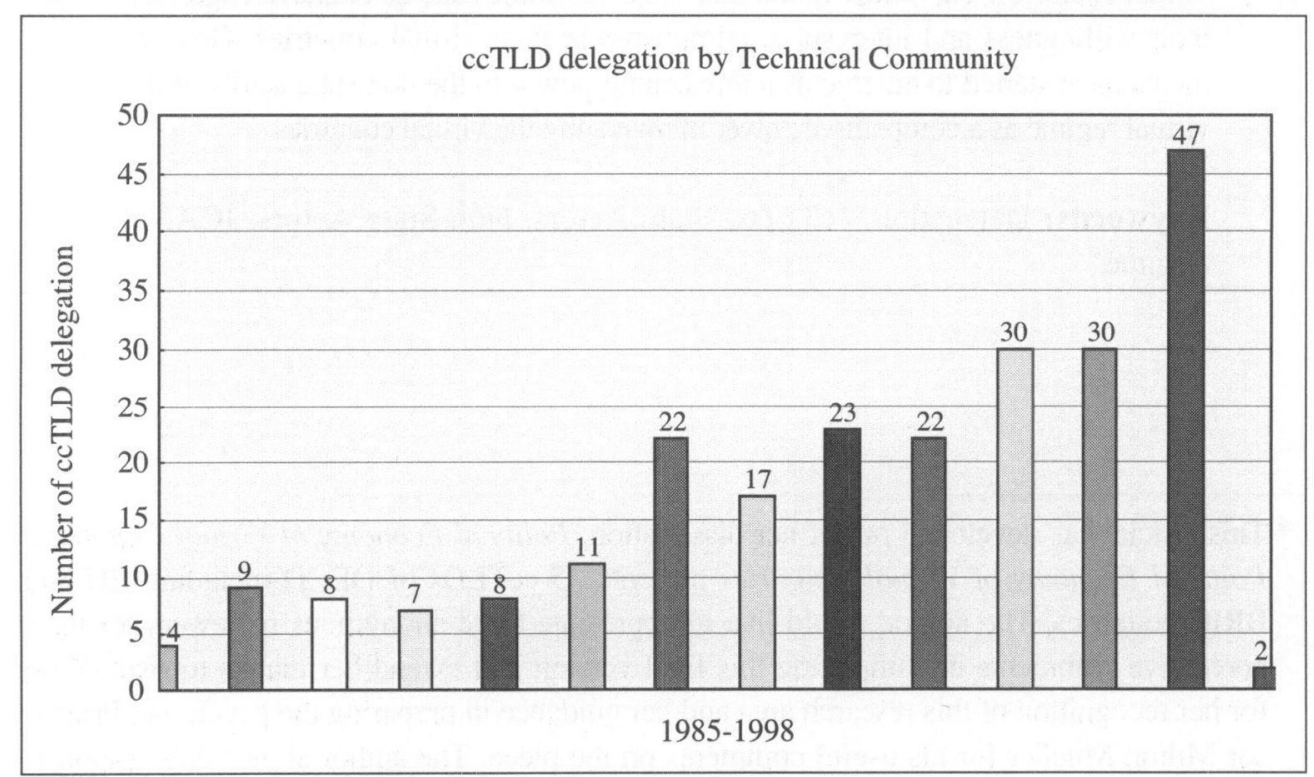

Source: IANA website http://www.iana.org/cctld/cctld-whois.htm.

1. The technical community has special status as a "technical liaison group" in the ICANN regime even though it was not clearly recognized by the UN World Summit on the Information Society. The practice of the ICANN regime was recently accepted by the OECD in preparing for the Ministerial Meeting on the Future of the Internet Economy, which will take place in Seoul in June 2008. According to OECD criteria, non-state actors comprise the categories of private sector, technical community and civil society. 
were appointed by Jon Postel to administer ccTLDs. Archival data on the Internet, as well as data from phone or email interviews with veteran engineers and ccTLD administrators, were used to unveil the early delegation process of the ccTLDs.

The second stage of ICANN's legacy delegation process started in 1998. Even though during this present period more data on delegation is publicly provided by Internet Assigned Numbers Authority (IANA), the details of the delegation process are still withheld by ICANN because of sovereignty issues between ICANN and the corresponding countries. The ICANN was built on the principle of leadership by the private sector or non-state-actors. Ironically, more state actors than non-state actors have been appointed by the ICANN to administer ccTLDs. In this study, the term state actors refers to the governments of individual states. US government in this study is represented as a hegemonic power of the regime creator. This article investigates why the ICANN regime is engaged with self-contradicting delegation to state actors as a private sector regime. This study explores whether the ICANN regime follows the power-oriented regime theory that places more emphasis on the role of state actors to maintain the regime more effectively.

\section{CONCEPT OF VIRTUAL COUNTRIES}

In this article, ccTLDs are referred to as virtual countries in order to emphasize the nature of the ccTLD space. The concept of virtual countries on the Internet was first discussed by a small group of engineers under the leadership of Jon Postel in 1978 (Cohen, 1978). "At the top level of the hierarchy there is the country code, and underneath it there are as many addressing schemes as there are countries. All countries (on the Internet) know how to communicate with any other country (on the Internet). In both systems addresses are of variable length, and by looking at an arbitrary address one cannot parse it into fields without knowing the specifics of each national addressing scheme."3

2. Internet Experiment Notes (IEN) 31 in 1978

3. ftp://ftp.rfc-editor.org/in-notes/ien/ien31.txt.

Here are some examples of telephone addresses and their correct parsing as COUNTRYNPA-CO-station:

1-213-822-1511 (USA, LA)

44-1-387-3400 (UK, London)

44-31-332-2424 (UK, Edinburgh)

44-745-58-3301 (UK, Wales)

972-4-25-2690 (Israel, Haifa)

972-67-4-0777 (Israel, Kiryat Shmona). 
The computer scientists as non-state actors introduced the concept of ccTLDs to build virtual countries on the Internet through their own rules, developed through Requests for Comments (RFCs), from 1981 to $1984 .{ }^{4}$ The creation of virtual countries was executed by Jon Postel in conjunction with research projects starting in 1985. After consulting with a small group of engineers, Postel designated who should be appointed to manage the virtual countries. This group was referred to as the Internet DNS Names Review Board (IDNB) in RFC 1591, written in 1994; the latter was considered the bible of virtual countries, although no formal record of this group exists. IDNB was supposed to act as "a review panel for cases in which the parties cannot reach agreement among themselves" but there is again no public record on IDNB and what decisions were made by the board. 5

What is an RFC? Many rules on the Internet have been set up through the Internet Engineering Task Force (IETF) process. These rules, called RFCs, are guidelines suggested by a group of engineers through the IETF consensus process. Not all RFCs are concerned with establishing technical standards. RFCs cover meeting notes, opinions, and even humor, as well as many aspects of computer networking. RFCs are categorized into the following four tracks: standard, best current practice, informational or experimental, and historic. Standard RFCs are official specifications of Internet protocol suites defined by the IETF. Best current practice RFCs are guidelines and recommendations but not standards from the IETF. Informational or experimental RFCs are non-standards documents and may originate in the IETF or may be independent submissions. Historic RFCs are former standards that have been actively deprecated.

The first RFC, written prior to the creation of the IETF, was a set of working notes about ARPAnet research and development. Three decades later, a group of Internet pioneers ${ }^{6}$ wrote RFC 2555 , "30 Years of RFCs" (RFC Editor et al., 1999). In that document, Steve Crocker, the author of RFC 1 "Host Software" (1969) recollected that "the early RFCs and the associated Networking Working Group laid the foundation

4. (1) RFC 799 Internet Name Domains (Mills, 1981), (2) RFC 819 The Domain Naming Convention for Internet User Application (Su and Postel, 1982), (3) RFC 881 The Domain Names Plan and Schedule (Postel, 1983), (4) RFC 882 Domain Names - Concepts and Facilities (Mokapetris, 1983), (5) RFC 883 Domain Names - Implementation and Specification (Mokapetris, 1983), and (6) RFC 897 Domain Name System Implementation Schedule (Postel, 1984).

5. Steve Goldstein from NSF, Randy Bush from NSRC, John Klensin from NSRC, Daniel Karrenberg from RIPE NCC, and Joyce Reynolds are believed to have been in Postel's circle.

6. Robert Braden, Joyce K. Reynolds, Steve Crocker, Vint Cerf, Jake Feinler, and Celeste Anderson coauthored RFC 2555. 
for the Internet Engineering Task Force." Crocker confessed, "I believed the notes were temporary and the entire series would die off in a year or so once the network was running." In 1969, Crocker was a graduate student at UCLA, and the RFC was a mere note. In RFC 2555, Crocker said, "I wanted to emphasize these notes were the beginning of a dialog and not an assertion of control." RFCs became a powerful assertion of control on the Internet. As of this writing, the latest RFC is RFC 5235, written in January 2008.

It must be noted that the Internet was not the only network when the virtual country project was planned and executed by Jon Postel. During the mid-1990s there still was competition between the Internet and Open System Interconnection (OSI). The Internet project was designed and controlled by non-state actors under the financial backing of the U.S. government. The RFCs created by the IETF have been voluntarily accepted by the engineers in the name of consensus. OSI, on the other hand, was developed by state actor-oriented international organizations such as the International Telecommunication Union (ITU) and supported by state actors. Many, therefore, predicted that OSI would be adopted globally. OSI's slow standardization process, however, failed to attract people to the OSI, while the Internet started to grow exponentially by virtue of its informal coordination mechanisms (Russel, 2006).

When the Internet was still in its experimental stage, English-language virtual countries were set up by non-state actors on the basis of RFCs under the coordination of Jon Postel. Until the mid-1990s, virtual countries were still experimental spaces in which the engineers could interact with each other around the globe. Even though there were commonalities, such as English-based design across virtual countries guided by the RFCs, in principle, virtual countries could be developed according to the appointed administrator's individual preference. As with the evolution of the Internet space from a military network to a research network to a commercial network, the identity of each virtual country is still being shaped by various stakeholders, from nonstate actors to state actors.

\section{The First Emperor of Virtual Countries, Jon Postel}

The virtual country project was masterminded by Jon Postel under the name of the Internet Assigned Numbers Authority (IANA), but public documents on the details of IANA were available until 1998. Postel attained his exalted position by not only creating a process of delegating each virtual country to the most "legitimate" party but also maintaining the empire of virtual countries until he died in 1998. His informal delegation process started in 1985, but his philosophy regarding delegation of virrtual countries was finally formalized as RFC 1591 in 1994. Postel and his group in the United 
States made decisions in the name of IANA, especially in the formal documents associated with the delegation of virtual countries. As of 2007, the formal record of how the IANA was created and who was involved with it is still not available. It was known that Jon Postel, together with Joyce Reynolds, managed the IANA function under its DoD contract from its inception until Postel's death. ${ }^{7}$ Both Postel and Reynolds were researchers or computer scientists at the Information Sciences Institute (ISI) of the University of Southern California (USC).

There are three theories regarding when the IANA was established. The first, that the IANA was created in 1990, is based on its first being mentioned in RFC 1060, “Assigned Numbers" (Reynolds, J. and Postel, J. March 1990). ${ }^{8}$ According to the second theory, based on a National Telecommunications and Information Administration (NTIA) document, the IANA was created in the early 1980s. According to the NTIA's presolicitation notice, DOCNTIA-000, dated on May, 18, 2006, "the IANA functions have been performed under contract with the Government for more than 25 years, previously under the auspices of the Department of Defense's Advanced Research Projects Agency (DARPA)." The third theory - that the IANA was created in 1972-was introduced by IANA staff, who stated that IANA was designed to be a definitive central coordinating body. RFC 322, "Well Known Socket Numbers" (Cerf, V. and Postel, J. March, 1972) refers to a registry function but does not make any specific reference to IANA. ${ }^{9}$

According to the seven-page RFC 1591, "Domain Name System Structure and Delegation" (Postel, 1994), the bible of ccTLD delegation before the ICANN regime, "the Internet Assigned Numbers Authority (IANA) is responsible for the overall coordination and management of the DNS and especially the delegation of portions of the name space called top-level domains." However, it was still a very informal institutional arrangement in the form of a contract between DARPA and USC as part of a research project known as the Terranode Network Technology (TNT). ${ }^{10}$ IANA's func-

7. http://en.wikipedia.org/wiki/Internet_Assigned_Numbers_Authority.

8. "This RFC will be updated periodically, and in any case current information can be obtained from the Internet Assigned Numbers Authority (IANA). If you are developing a protocol or application that will require the use of a link, socket, port, protocol, etc., please contact the IANA to receive a number assignment. Joyce K. Reynolds Internet Assigned Numbers Authority USC - Information Science Institute 4676 Admiralty Way Marina del Rey, California 90292-6695"

9. "we would recommend that it be maintained at NIC" Dr. Vint Cerf or Jon Postel 3804 Boelter Hall UCLA Computer Science Department Los Angeles, California 90024

10. "As the TNT project neared completion and the DARPA/USC contract neared expiration in 1999, the Government recognized the need for the continued performance of the IANA 
tions were known to be carried out by Jon Postel and Joyce Reynolds. Postel continued delegating virtual countries to non-state actors.

Given the above three different theories of when IANA was created, four different stages of IANA can be studied: (1) 1972-early 1980s, ${ }^{11}$ (2) early 1980s-1990, (3) 1990-1998, and (4) 1998-present. In the context of Jon Postel's delegation of virtual countries, this study considers the IANA from 1985 to 1998 to be Postel's operation. In the context of ICANN's delegation of virtual countries, this study regards the management of IANA from 1998 to the present as operating under the supervision of the U.S. government (USG).

\section{Creation of Virtual Countries Based on ISO 1366-1 List}

Postel and his group decided to adopt the ISO 3166-1 list for their list of virtual countries so that they could avoid political decisions regarding whether parties who wanted to create virtual countries for their own countries had legitimate requests. The initial ISO 3166 list was created by a small group of experts from Europe in 1968. The ISO 3166 Maintenance Agency was created in 1976 to maintain the list. Even though ISO 3166 is known to be very stable and changes are made only when necessary, decisions regarding which country codes to include are associated with embedded political decisions. Not every country name change calls for a new code element. From 1976 to 2001 , only 26 country names were deleted completely from ISO 3166 . For example, the unification of Germany and the breakup of the Soviet Union and Yugoslavia into new independent countries led to changes in the ISO 3166 list. The fourth edition of the ISO 3166-1 list was published in 1993, consolidating political changes in the list.

In principle, the ISO 3166-1 list is based on the United Nations Statistics Division's list. The UN list consists of codes given in the UN Bulletin "Country Names" and in the code list of the "Standard Country or Area Codes for Statistical Use." ISO added the following to their list of virtual countries: the Norwegian territory Bouvet Island $(. B V)$; the British territories British Indian Ocean Territory (.IO) and South Georgia and the South Sandwich Islands (.GS); the Australian territories Christmas Island (.CX), the Cocos Islands (.CC), and Heard Island and McDonald Islands (.HM); the French territory the French Southern Territories $(. T F)$; and the United States' territories the United States Minor Outlaying Islands (.UM) and Antarctica (.AQ).

The ISO 3166-1 list is somewhat peculiar as a reference in deciding what are coun-

functions as vital to the stability and correct functioning of the Internet." (SOW)

11. There was no specific institutional arrangement of IANA and the concept of IANA's functions emerged. 
tries and what are not, and thus it confuses people as to what codes are entitled to be created as virtual countries and what codes are not. The "ISO 3166-1 list is plainly not '(the list of) countries' at all, but are instead dependencies of other countries. Examples include Heard Island and McDonald Islands .HM (a territory of Australia), Netherlands Antilles .AN (part of the Kingdom of the Netherlands), and Puerto Rico .$P R$ (a commonwealth associated with the US). The country code for Antarctica . $A Q$, which also appears on the ISO 3166-1 list, has also been established and delegated."12

The ISO 3166-1 list does not include the Channel Islands and Isle of Man, which are on the UN list. Those codes later appeared in the ISO reserved list as .GG and .JE for Channel Islands and .IM for Isle of Man. How could two codes be created for the Channel Islands, which are not even a member state of the UN? Three of the codes were adopted as virtual countries from the ISO reserved list. Another six reserved ISO codes are Clipperton Island (.CP), Diego Garcia (.DG), Ceuta and Melilla (.EA), Metropolitan France (.FX), Canary Islands (.IC), and Tristan de Cunha (.TA). Today ISO decides what is or is not considered a country on the Internet.

More confusingly, Postel used the ISO 3166-1 list as a main reference in creating virtual countries, but he also used the ISO 3166-1 reserved list, which was from time to time without clear rules. There are fourteen codes in the reserved list. Seven virtual countries out of fourteen were created from the reserved list: Ascension Island $(A C)$, Aland (.AX), European Union (.EU), Guernsey (.GG), Isle of Man (.IM), Jersey (.JE), and the United Kingdom (.UK). Of these seven virtual countries, five are under the United Kingdom's sovereignty. Aland Island belongs to Finland. According to Postel's email on Country Code Top Level Domains in November 1996, it was an arbitrary decision. "This small extension of the rules by the IANA ${ }^{13}$ seemed to greatly offend very few people, and seemed to be no big deal to many others. A key point to keep in mind is that the IANA did not choose the codes or make up the list, it extended the set of allowed codes to another list provided by the ISO 3166 maintenance agency."14

The following . $G B$ case illustrates that in the beginning even the emperor of the virtual countries did not know the ISO 3166-1 list well enough, and then it was too late for him to change his own legacy decision. There is a historical virtual country, Great Britain .GB, on the Internet, even though it was never used actively in its history as a virtual country. Peter Kirstein, the original caretaker of . $U K$ and.$G B$, explained in

12. http://www.icann.org/general/ps-report-22mar00.htm.

13. $\mathrm{AC}=$ Ascension Island, $\mathrm{GG}=\mathrm{Guernsey}, \mathrm{IM}=$ Isle of Man, $\mathrm{JE}=\mathrm{Jersey}$.

14. Jon Postel's email was forwarded in John Charles Broomfield's message to General Assembly of DNSO list on March 21, 2000 under the subject of ISO-3166 and reserved codes http://www.dnso.org/clubpublic/ga-full/Arc00/msg00943.html. 
an email interview why . $G B$ was not chosen for his country even though it was on the ISO list. "I chose .UK, because it was the correct description of my community. Nobody had the slightest concept of ISO-3166. After 1986 or maybe 1987, Jon Postel tried to put some order into the system, and informed me that I would have to use the correct ISO-3166 code. I therefore registered .GB also."

Kirstein also recollected that Postel had asked him to change the code of the virtual country of United Kingdom from .UK to . $G B$, which would have required users of the .UK domain to migrate to .GB. "The British authorities objected strongly to the idea that Jon should force them to change what they were doing, and I had lengthy arguments with Jon on the matter. While we had both, the Ministry of Defense started having more users, and did not wish to risk changing later. They thought I would lose my argument, so they registered many users under.GB. We had one big intra-government meeting on the matter which included some eight of our ministries; I think it was around 1988. They decided even then that it would cost UK£25 Million to make the change from . $U K$ to . $G B$, and refused to do so. I finally agreed with Jon Postel to change within about 5 years - and also offered to change within one week of all the US moving to .US (Jon did not think this funny!). By the time the five years were up, I was no longer running the domain, so I think all the agreements were forgotten."

According to Kirstein, Willie Black of the UK Education and Research Networking Association (UKERNA) managed the virtual countries of the United Kingdom from 1996 until he retired in 2004. It is not certain how .GB remained a historical virtual country under Black's tenure, but Kirstein shared how . $G B$ was used in the early days. "I do not remember the reason for the Oxford group; anyone was free to register domains under. $G B$ just as much as under. $U K$ during those years. I know two Oxford groups had links with NASA (through me); I do not remember if these were they. Bob Cooper (Head of UKERNA) and I (and Klaus Ullman, the Head of the German DFN, and Vint Cerf) were a UN Development Programme Review Committee for an Indian project which was called the ERNET project, and later led to the current Indian NREN; this was 1988-1992. I seem to remember that Bob offered to let the Indians come in directly to the British JANET network over a leased line, and probably let them come in over . $G B$ because that was the correct ISO designation. Around that time some UKERNA people even proposed that .GB be used for the OSI protocols and.$U K$ for the Internet ones; needless to say I was strongly against this proposal. I think .GB still exists on paper; for all I know I may be responsible for it still."

Later, under the USG, IANA faced other kinds of historical virtual countries as the result of political changes updated by ISO. Some historical country codes such as Zaire.$Z R$ disappeared from the Internet voluntarily upon the request of IANA. .ZR is no longer available. Instead, the Democratic Republic of Congo . $C D$ replaced .ZR. 
Another transition, from .TP (Portuguese Timor) to .TL (Timor Leste), was made in 2005 . However, the.$S U$ community for the Soviet Union, under the leadership of the .$S U$ registry, does not want to disappear from the Internet. IANA staff tried to talk with the.$S U$ operators, hoping for their voluntary cooperation to agree that no further domain names under.$S U$ would exist on the Internet. However,.$S U$ operators keep providing its service to the users of . $S U$, even as Russian . $R U$ operators serve the users of . $R U$. Indeed, many registrars in Russia also serve as agencies for registering domain name holders. Technically, there is a way to retain . $S U$ under current IANA practice. As long as .SU is reinstated into the ISO 3166-1 standard, either as a regular two-letter country code or as an "exceptionally reserved" code like .UK and .EU, IANA cannot force that virtual country to disappear from the Internet.

\section{The First Virtual Cointry,.US, on the Internet in 1985}

The initial five generic top level domains (gTLDs)-.ARPA, .GOV, .EDU, .COM, and .ORG-were proposed together with country codes for virtual countries and domains for multiorganizations in RFC 920, "Domain Requirements" (Postel and Reynolds, 1984)..$^{15}$ RFC 1032 confirmed another gTLD name, .NET, for various network-type organizations and infrastructure. As a result of the consensus on creating virtual countries on the Internet among the small number of engineers in the Imoted States and a few engineers from Europe and Asia who were invited for regular brainstorming meetings to expand the Internet, the virtual country project was finally launched in 1985. Kilnam Chon, a computer scientist appointed to administer .KR for Korea, recollected during a phone interview that around 20 engineers who maintained the network around the world had regular meetings once a year. Chon said that he was

15. According to RFC 920, "An initial set of (generic) top-level names has been identified. Each of these has an administrator and an agent." The following top level domains were suggested to be administered by DARPA and operated by The Network Information Center.

ARPA $\Rightarrow$ The ARPA-Internet (Temporary), GOV $\Rightarrow$ Government, EDU $\Rightarrow$ Education, $\mathrm{COM}=>$ Commercial, MIL $\Rightarrow$ Military, ORG $\Rightarrow$ Organization Countries.

RFC 920 also explained the concept of country names on the Internet for the first time. "The English two letter code (alpha-2) identifying a country according to the ISO standard for codes for the representation of names of countries. As yet no country domains have been established. As they are established information about the administrators and agents will be made public, and will be listed in subsequent editions of this memo." But there was neither public announcement nor subsequent memo on this.

There was another category for multiorganizations in RFC 920. This seems to be developed into .INT for international organizations later. 
also invited to attend the 20th anniversary NSF Backbone Network in Washington DC in 2007, which was supposed to have been held in 2006.

The first virtual country, .US for the United States, was delegated by Postel to himself in February 1985. RFC 1480, "The US Domain" (Cooper and Postel, 1993) also confirmed "the domain administrators (of the .US) are Jon Postel and Ann Westin Cooper at the Information Sciences Institute of the University of Southern California." Peter Kirstein from the United Kingdom, the first appointee for .UK and .GB, recollected in his email in 2007, "However, .US was hardly used. From the beginning, all US educational establishments used .EDU, military, .MIL, and commercial, .COM; as a result even though .US existed, it was hardly used."16

\section{Non-State Actors Appointed to Administer Virtual Countries}

Even though it was understood that state actors would play a main role in the global virtual regimes, it was noted that non-state actors should also play a substantial role in maintaining the global regimes (Haufler, 1993). Traditionally, the global regime is created and maintained by state actors. The most unique aspect of the global virtual country regime is not the state actors but the role that the non-state actors played in creating and maintaining the regime until 1998, when the Internet came under the USG's supervision. It has been only 22 years since the first virtual country, .US, was created by Postel in 1985. As of 2007, 250 virtual countries have been delegated to countries and territories. Only one virtual country, Western Sahara .EH, has not yet been delegated, and one virtual country, .TL (Timor-Leste), is conflicting with its previous name, .TP (Portuguese Timor).

It is still difficult to find public records on how virtual countries were delegated to the non-state actors. The following three hypothetical delegation scenarios were suggested by John Klensin, one of the senior members of the Internet community. Klensin also wrote RFC 3071, "Reflections on DNS," RFC 1591, and Categories of Domain Names in 2001. "(A) There was actual Internet connectivity into the country, with hosts working and names typically in .EDU and/or .NET. An application arrived from an already known researcher or administrator who was known to lead/represent the national Internet community. It specified at least one server inside the country and identifies arrangements for one or more secondary servers, of known reliability, outside the country and on other networks. The ccTLD was then registered with a minimum of fuss. (B) There was no Internet connectivity within the country, although there might have been big plans. There was not much network research community,

16. Email Interview with Peter Kirstein. 
either. In extreme cases, the application did not come from inside the country but from some outside entity with good intentions. A lot of questions were asked about who was intended to be connected (and why they were not listed on the application), what value a ccTLD is going to provide, and why. If the answers were not satisfactory, the response to the request for delegation was typically 'later.' (C) Cases in which there were multiple entities who wanted to be the ccTLD administration in a country, often for bad reasons (like locking the customers of other ISPs out), fell somewhere in between the two cases above. Controversies were settled by a 'work it out yourselves and come back when there is national agreement' policy, which sometimes resulted in the in-country people asking their governments to help them work things out (or decide for them)."

RFC 1032 introduced and specified the mechanism for how to request country code domains to build virtual countries in more detail than RFC 920.

Countries that wish to be registered as top-level domains are required to name themselves after the two-letter country code listed in the international standard ISO-3166. In some cases, however, the two-letter ISO country code is identical to a state code used by the U.S. Postal Service. Requests made by countries to use the three-letter form of country code specified in the ISO-3166 standard will be considered in such cases so as to prevent possible conflicts and confusion.

There was a questionnaire to fill out in the RFC 920 if an entity wanted to manage a top-level domain name, but it was not clear whether the form could be applied to ccTLDs. ${ }^{17}$

17. In that questionnaire in the RFC 920, there were (1) the name of the top level domain to join, e.g., .EDU, and (2) the name, title, mailing address, phone number, and organization of the administrative head of the organization. In the case of a research project, this should be the Principal Investigator, e.g.,

$\begin{array}{ll}\text { Administrator } & \\ \text { Organization } & \text { USC/Information Science Institutes } \\ \text { Name } & \text { Keith Uncapher } \\ \text { Title } & \text { Executive Director } \\ \text { Mail Address } & \text { USC/ISI 4676 Admiralty Way, Suite 1001 Marina del Rey, CA. } \\ & 90292-6695 \\ \text { Phone Number } & 213-822-1511 \\ \text { Net Mailbox } & \text { Uncapher@USC-ISIB.ARPA } \\ \text { NIC-Ident } & \text { KU }\end{array}$

(3) the name, title, mailing address, phone number and organization of the domain technical contact, e.g., 
The delegation scenario of virtual countries can be reconstructed according to the recollections of Klensin, Kirstein, and early RFCs. Engineers around the world started to send application to administer their virtual country after they had learned about Postel's virtual country project on the Internet. A small group of engineers under Postel's leadership determined whether an applicant who had applied to administer a virtual country had legitimate rights and should be appointed to administer it. Even though in 1994 RFC 1591 described the requirements of residence in the country and responsibilities of the designated manager for virtual countries, ${ }^{18}$ Postel and his group were willing to appoint those who did not live in the countries to administer virtual countries, especially in the case of African countries. Michuki Mwangi, chair of the Africa Country Code Top Level Domain Forum (AFTLD), confirmed that "many virtual countries from Africa are in the process of correcting the situation."

\begin{tabular}{ll}
\multicolumn{2}{l}{ Technical Contact } \\
Organization & USC/ISI \\
Name & Craig Milo Rogers \\
Title & Researcher \\
Mail Address & USC/ISI 4676 Admiralty Way, Suite 1001 Marina del Rey, CA. 90292- \\
& 6695 \\
Phone Number & $213-822-1511$ \\
Net Mailbox & Rogers@USC-ISIB.ARPA \\
Nic-Ident & CMR
\end{tabular}

(4) the name, title, mailing address, phone number and organization of the zone technical contact. This is the contact point for problems with the zone and for updating information about the zone. In many cases the zone technical contact and the domain technical contact will be the same person. (5) the name of the domain (up to 12 characters), e.g., ALPHABETA (6) a description of the servers that provide the domain service for translating name to address for hosts in this domain, and the date they will be operational, e.g., Our server is a copy of the server operated by the NIC, and will be installed and made operational on 1November-84. (7) a description of the server machines, including: (a) hardware and software (using keywords from the Assigned Numbers) (b) addresses (what host on what net for each connected net) i.e.

(a) hardware and software: VAX-11/750 and UNIX, or IBM-PC and MS-DOS

(b) address: 10.9.0.193 on ARPANET

(8) an estimate of the number of hosts that will be in the domain. (a) initially, (b) within one year, (c) two years, and (d) five years, e.g., (a) initially $=50$, (b) within one year $=100$, (c) two years, and $=200$, (d) five years $=500$. The updated questionnaire in RFC 1032 requires the following two questions: (9) the date you expect the fully qualified domain name to become the official host name in HOSTS.TXT (10) a description of your organization.

18. "The designated manager (for a ccTLD) should be able to carry out necessary responsibilities and have the ability to do a equitable, just, honest, and competent job." 
Thirty-seven virtual countries were delegated by Jon Postel to non-state actors without consultation with state actors from 1985 to 1990 . It should be noted that 26 virtual countries were delegated to 25 OECD member states during this period. ${ }^{19}$ In other words, more economically advanced countries were able to obtain virtual countries earlier than other countries. Peter Kirstein, the first administrator of the virtual country of United Kingdom .UK shared his experience of working with Postel. "We were all one family. It was not a question of 'getting in touch with him.' Paul Mockapetris ${ }^{20}$ was my DARPA Project Manager at one time and he had worked with Jon. I worked with ISI continually. I was the first person to run Internet services from 1981, long before the DARPA community went over to IP."

Political detente allowed Postel to expand the Internet to the Soviet Union and former communist countries and to the People's Republic of China in 1990. The NSFNET Backbone Project (1987-1995) was coordinated by Postel and his group. A conditional decision to get connected to those countries was made. ${ }^{21}$ The following countries were connected to the Internet: Poland in July 1990 and China and Hungary in November 1990, followed by Albania and Slovenia in April 1992; Cuba, Estonia, Lithuania in June 1992; Georgia and Ukraine in December 1992; Czech Republic in January 1993; Romania in February 1993; Slovak Republic in March 1993; Latvia in April 1993; Azerbaijan in August 1993; Macedonia in September 1993; Russia and Vietnam in April 1994; Kazakhstan in September 1994; Bulgaria in January 1995; Uzbekistan in April 1995; Kyrgyzstan in July 1995; Turkmenstan in May 1997; and Tajikstan in December 1997.

\section{New Coordinator of Virtual Countries, ICANN/USG}

With the creation of ICANN in 1998, the administrators appointed by Postel met for the first time with the administrators of other virtual countries without their emperor. They were asked by USG to build the ccTLD constituency, an institution for virtual countries, under the ICANN's auspices. IANA was designed as a part of the ICANN structure also. Finally, a formal institutional arrangement of IANA under ICANN became public in 1998. Starting with the USC/ICANN Transition Agreement in $1998,{ }^{22}$ ICANN entered into a series of agreements with the U.S. Department of Com-

19. Poland (1990), Turkey (1990), Hungary (1990), Czech Republic (1993) and Luxembourg (1995).

20. Inventor of Domain Name Systems.

21. Workshop on Member States' experiences with ccTLD: ccTLD Doc 55 Rev.1.

22. "On December 24, 1998, USC entered into a transition agreement with the ICANN under 
merce (DoC) on February 8, 2000; March 21, 2001; March 13, 2003; and most recently on August 11, 2006, with another five-year IANA contract. The administrators of virtual countries from Europe have expressed their interest in managing IANA from time to time. Nigel Roberts from Guernsey .GG said at the Shanghai ccTLD meeting in October 2002, "Let's stop playing the ICANN game and set up IANA function as the IANA contracts runs out."

Despite the interest expressed by the European virtual countries, there was no meaningful public competition process when the USG was awarded control of IANA. ICANN invited concerns regarding the DoC/NTIA's purchase of IANA in $2000^{23}$ and

which ICANN secured directly from USC, all necessary resources, including key personnel, intellectual property, and computer facility access critical to the continued performance of the IANA functions."

23. The attached letter has been sent to Janet Reno and Joel Klein at the U.S. Department of Justice; The U.S. Inspector General; The U.S. General Service Administration and the G.A.O.; and the House and Senate Appropriations, Ethics, and Commerce Committees.

February 26, 2000

Dear

The U.S. Department of Commerce and its National Telecommunications and Information Administration are engaged in an illicit process to give regulatory control of the Internet to special interests in violation of the White Paper on the Internet and of federal antitrust, administrative, and contracting laws.

For example, they are using incorrectly granted government contracts to escape debate, accountability, and Congressional oversight.

As well as being an illegal use of the U.S. Government's contracting authority (because the regulation of communications is not a service or good within the meaning of the laws that define the federal government's purchasing power), purchase order No 40S8NTO67D20 (NTIA/ICANN) for the delegation of Internet address allocation authority - is in violation of Federal Acquisition Regulations (48 CFR Chapter I (See below)) for the following reasons:

1) There were no competitors for the contract;

2) The offer was not made publicly;

3) The contract was not put out for bids;

4) The supposed service being contracted is not a service but a regulatory function falling under the Commerce Clause of the U.S. constitution, and thus cannot be contracted without Congressional legislation, and is not within the charter of the NTIA;

5) Contractor NTIA's representative, Beckwith Burr, was instrumental in formation of ICANN, the recipient of the contract;

6) Burr is personally acquainted with companies and individuals financing recipient ICANN and has facilitated its acquisition of the contract;

7) Burr has nor ensured that recipient ICANN conform to contract requirements of the 
in 2003. ${ }^{24}$ Longtime ICANN observer A. Michael Froomkin also questioned the sincerity of the DOC/NTIA's public comments process in 2003: "How do you have price competition on a zero-dollar procurement?"25 DoC allowed only 10 days for public comments on the zero-dollar procurement contract to ICANN. Most Internet users or governments who did not pay close attention to DoC's notice were not aware of the purchase process of IANA under the coordination of DoC.

As the first CEO of ICANN, Mike Roberts, remarked at a 2001 Senate hearing, the $244^{26}$ virtual countries at that time were very diverse: "Some like Germany . $D E$ or Great Britain.$U K$ are large and active registries (of virtual countries); some like Antarctica . $A Q$, have almost no registrations at all; and some are completely inactive. In addition, the way the ccTLDs (virtual countries) are operated varies enormously. Some are highly restricted to residents or citizens of that particular country, while others are completely unrestricted. Some are restricted."

NTIA specifically that recipient be a membership organization representative of a consensus of service stakeholders including users;

8) Burr sits on an advisory committee of recipient ICANN (the Governmental Advisory Committee (GAC)), which is a per se organizational conflict;

9) The CEO of the recipient - ICANN President Michael Roberts - is the representative of an organization (EDUCAUSE) contracting services with ICANN that fall within those subject to purchase order No 40S8NTO67D20, and Mr. Roberts is therefore in conflict of interest with the award;

10) Members of ICANN's Board of Directors are representatives of special interests, such as IBM that have unfair competitive advantage in controlling the contracted Internet services.

[snip]

Michael Sondow (for the ICIIU).

24. Workshop on Member States' Experiences with ccTLD Doc 28 Extension of contract between IANA and ICANN.

"I (Willie Black, Executive Chairman of Nominet) do not believe that ICANN is the only body capable of carrying out the IANA function. Particularly in view of ICANN's track record of not clearly separating its policy consensus-making role from its operational role, I believe some consideration should have been given to consulting more widely with the affected community of Top Level Domain managers on the important requirements of the function before entering into a 3 year, sole-tender contract."

"Nominet is concerned that such a short period has been given to allow alternative solutions to be elaborated, publicized and industry support sought so that they could be evaluated in comparison to the proposals from ICANN."

25. http://www.icannwatch.org/article.pl?sid=03/02/08/2153213\&mode=thread.

26. The number of virtual countries (ccTLDs) has been changed. It was 244 in 2001 and was increased into 251 in 2007. 
In principle, virtual countries are represented in the form of ccTLDs. But there are some exceptions. Some countries or political entities are represented by gTLDs. Because of the leading role of the United States in DNS history, the United States can use the Generic Top Level Domains (gTLDs) of .GOV, .EDU, ${ }^{27}$ and .MIL as well as .US on the Internet. Only institutions in the United States can use .GOV, .EDU and .MIL as of 2007.

When .EU for European Union was approved by the ICANN board back in 2000, it was entered as a ccTLD instead of a gTLD. ICANN recognized its special political status as a country. But the actual delegation of.$E U^{28}$ on the Internet was made in April 2005. Although "the EU had announced its plan to introduce a new ccTLD in 1999," it took seven years for EU to have an existence on the Internet (von Arx and Hagen 2002).

ICANN on the other hand approved the new gTLD .CAT for the Catalan community in September 2005. As Christopher Wilkinson paved the way to create .EU as a ccTLD, former ICANN board member Amadeu Abril i Abril coordinated the .CAT creation process. The people from Catalonia, which is not internationally recognized, could have their own top level domain. ${ }^{29}$

\section{State Actors Appointed to Administer Virtual Countries}

Since 1998, ICANN has formally delegated the following seven virtual countries: Bangladesh . $B D$ in 1999; Palestine Territories .PS in 2000; European Union .EU in 2005; Aland Island . $A X$ in 2006; and Serbia .RS, Montenegro .ME, and North Korea

27. http://www.educause.edu/edudomain/show_faq.asp?code=EDUELIGIBILITY. Eligibility for an .edu domain name is limited to post-secondary institutions that are institutionally accredited, i.e., the entire institution and not just particular programs, by agencies on the US department of Education's list of Nationally Recognized Accrediting Agencies. Some non-US educational institutions, such as the University of Toronto and the United Nations University, retain their registrations from an earlier, less restrictive time. Also, registrations from foreign but US-accredited educational institutions are currently being accepted (OECD 2006 Report).

28. .eu is one of the latest country codes. eu already counted over 1.5 million names after only one week of opening to the public and in September 2006 counted over 2 million. The Brussels-based European Registry of Internet Domain Names (EURid) is a consortium of five ccTLD registries: Belgium, Czech Republic, Italy, Slovenia and Sweden. (OECD 2006 Report on Evolution in the Management of Country Code Top Level Domain Names (ccTLDs)).

29. http://www.circleid.com/posts/the_catalan_campaign_to_win_cat_top_level_domain/. 
.$K P$ in 2007. Except in the case of Serbia, state actors asked for the rights to administer their virtual countries, and their requests were accepted by ICANN. "The Regional Government of Åland and the Finnish Ministry of Transport and Communications first approached IANA in late 2005 to enquire as to the procedures for delegation of the . $A X$ domain name. On 9 June 2006 the ICANN Board of Directors authorized the President of ICANN to move forward with the delegation of the .AX top-level domain to the Regional Government of Åland." 30

As of 2007, the administrator of .ME is Vujica Lazovic, Deputy Prime Minister for economic policy, Government of Montenegro; the administrator of .PS is MTIT Representative, PNINA Chairman, Ministry of Telecommunications \& Information Technology, Palestinian Territory, Occupied; the administrator of . $B D$ is Director Telecom, Ministry of Post \& Telecommunications; and the administrator of .KP is Kim Chang Ryop of the Korea Computer Center.

\section{Creation of Virtual Regions}

The concept of creating.ASIA was prompted by the.$E U$ case. If there is a specific cyberspace for citizens and entities in the European Union, why not extend such a concept to other regions? There are two main obstacles for other regions in creating their own regional codes on the Internet. The first challenge is whether ISO is willing to accommodate the request from each region and update it on the ISO 3166-1 list for ccTLDs. "EU is not an official ISO-3166-1 country code, but since many users of ISO-3166-1 have a practical need to encode the 'eu' name, the ISO 3166 Maintenance Agency (MA) reserved the two-letter combination EU for the purpose of identifying the European Union within the framework of ISO 3166-1" (OECD 2006 Report).

The second challenge to implementing a regional code, especially in Asia, was whether a solid regional governmental coordination body existed for Asia as in the EU. After the creation of .EU, there were various speculations in the Internet community regarding who would coordinate .ASIA or .AP. APEC was one of the options, but APEC is a coordination body for countries in the Pacific rim including Chile, the United States and Mexico, who do not belong to Asia or Asia Pacific. ASEM was another option, but ASEM is a coordinating body for countries both in Asia and in Europe. ASEAN was another option as a potential coordination body for .ASIA if it includes China, Japan and Korea. The idea of ASEAN +3 was never explored.

Such a gap encouraged a private Hong Kong-based company, DotAsia Organisation Limited, associated with Affilias, ${ }^{31}$ a world-wide virtual country outsourcing reg-

30. http://www.iana.org/reports/ax-report-09jun06.pdf. 
istry, to apply for .ASIA as a Sponsored Top-Level Domain (sTLD) in 2004. ICANN started to add new gTLDs from 2000 and proposed to differentiate sponsored TLDs from unsponsored TLDs in 2003..$^{32}$ Each sTLD had to identify its sponsoring organizations that could sign a contract with ICANN to take responsibility for administering the sTLD. According to the .ASIA application form, the sponsor members of .ASIA are "organizations in the Pan-Asia and Asia Pacific region defined by ICANN's Asia/ Australia/Pacific region that manage and operate any of the country code top level domain registries in the region," 33 and .ASIA would serve "the Pan-Asia and Asia Pacific community."

Even though .ASIA functions similarly to its counterpart .EU, .ASIA was approved by the ICANN board as a gTLD (2006), not as a ccTLD. This was briefly controversial at the Governmental Advisory Committee of ICANN, because the proposal of .ASIA had nothing to do with governments in Asia. ${ }^{34}$ But because loosely participating Asian governments could not respond to such a proposal effectively, the ICANN board was willing to approve .ASIA, seeing it as an additional chance to impose more binding relations with ccTLDs in Asia.

31. Afilias is a strong player in providing registry services for both gTLDs (.info and .org) and ccTLDs that include .AG (Antigua and Barbuda), .GI (Gibraltar), HN (Honduras), .IN (India), .LA (Laos), .SC (The Seychelles), and VC (St. Vincent and the Grenadines). Afilias also provides ancillary support to other domains including .SG (Singapore) and .BZ (Belize).

32. .AERO, .BIZ, .COOP, .INFO, .MUSEUM, .NAME, .PRO in 2000. An unsponsored TLD operates under policies established by the global Internet community directly through the ICANN process, while a sponsored TLD is a specialized TLD that has a sponsor representing the narrower community that is most affected by the TLD (Status Report on the sTLD Evaluation Process).

33. According to application, a number of letters-of-intent (LOI) have already been established between the organization and prospective sponsor (ccTLD) members and co-sponsor members. These include: CNNIC (.CN:China), JPRS (.JP:Japan), MONIC (.MO: Macao), IUSN (.NU:Niue), TWNIC (.TW:Taiwan) VNNIC (.VN:Vietnam), ccTLD-ID (.ID: Indonesia), APNIC (Asia Pacific Networking Group). Seven ccTLDs participated in .ASIA's application.

34. In August 2005, Howard C. Dickson, the GAC representative for the Hong Kong SAR, sent a letter to Che-Hoo Cheng, the Interim CEO of DotASia. Mr. Dickson's letter stated that (1) we "think that ICANN and DotAsia should address the issues and considerations before governments could take a definitive view on the support or otherwise for the proposal" and (2) we have "reservation for a private company to oversee and administer a regional TLD in general." The letter continues that "having said that, we do not have sufficient grounds to respond to the format as DotAsia proposed, that is support, have no objection, or object to, the Proposal." 
The existence of different rules and contractual relationships continues. Virtual countries have more independent power than gTLDs in the context of their relationship with ICANN. There is no mandate for a virtual country to sign a contract with ICANN/USG, but every gTLD is required to sign a contract with ICANN/USG. The content of a gTLD contract is proposed and crafted by the ICANN staff; therefore, .ASIA as a sTLD (gTLD) has to sign a contract with ICANN and it has little room to negotiate its terms with ICANN. On the other hand, .EU enjoys independence in deciding whether it wants to sign a contract with ICANN as a virtual country.

\section{The Legacy of the Global Political Economy}

In principle, every virtual country should be equal, because the country code itself has no dimension of power associated with territorial size. In reality, the dynamics of territorial politics seem to be translated into nonterritorial virtual country politics, so one would not be surprised at how the current UN Security Council member states, such as the United States, the United Kingdom, France, and China, have ensured their sovereignty over their respective virtual countries on the Internet. The ISO 3166-1 list has 244 countries and territories, whereas the United States Department of States recognizes 193 states as sovereign states in the world as of 2006. ${ }^{35}$ That leaves 51 ccTLDs that belong to other sovereignties or to Antartica. ${ }^{36}$ It should be noted that many nonsovereign territories are self-governing entities that have de facto external relations with other entities, although officially these are conducted by the parent state.

35. UN as of 2006 is composed of 192 member states.

36. The list is as follows: 1. American Samoa (US), 2. Anguilla (UK), 3. Aruba (Netherlands), 4. Bermuda (UK), 5. Bouvet Island (Norway), 6. Cayman Islands (UK), 7. Christmas Island (Australia), 8. Cocos Islands (Australia), 9. Cook Islands (New Zealand), 10. Falkland Islands (UK), 11. Faroe Islands (Denmark), 12. French Guiana (FR), 13. French Polynesia (FR), 14. Gibraltar (UK), 15. Greenland (Denmark), 16. Guadeloupe (France), 17. Guam (US), 18. Gurnsey UK (British Crown Dependency) 19. Heard and McDonald Islands (Australia), 20. Hong Kong (China), 21. Isle of Man (UK,BCD), 22. Jersey (UK, BCD), 23. Macau (China), 24. Martinique (France) 25. Mayotte (France) 26. Monteserrat (UK) 27. Netherlands Antilles (Netherlands), 28. New Caledonia France, 29. Niue New Zealand, 30. Norfok Island Australia, 31. Northern Mariana Islands (US), 32. Pitcairn Islands (UK), 33. Puerto Rico (US), 34. Reunion (France), 35. Saint Helena (UK), 36. Saint Pierre and Miquelon (France), 37. South Georgia and the South Sandwich Islands (UK), 38. Svalbard and Jan Mayen (Norway), 39. Tokelau (New Zealand), 40. Turks and Caicos Islands (UK), 41. Virgin Islands (US), 42. Virgin Islands (UK), 43. Wallis and Futuna (France), 44. Aland Islands (Finland), 45. Western Sahara, Palestine, Taiwan (To be determined). 
Just before the ICANN meeting in Wellington, New Zealand, in 2006, the following email was circulated on the ccTLD list by Chris Disspain of Australia .AU, the chair of the Country Code Names Supporting Organization (ccNSO). He intended to facilitate discussion in the non-state-actor oriented ccTLD community regarding whether the "principle of non-intervention of virtual countries" should be respected or violated under specific conditions. The email referred to a real situation but used other names.

Gondwanaland is a developing country. It's country code is .go and the ccTLD manager is David Keithson. David was born in Iceland but has lived in Gondwanaland for 30 years. Many years ago when the internet was in its infancy he applied to Jon Postel to be the ccTLD manager for .go and has been running it ever since in his spare time. David has, over the years, developed some policy for names in .go and names are readily available to those that want them. David does charge a small fee for each name every 12 months and that money goes to defray the costs of running .go.

The economy of Gondwanaland is growing. The government is democratically elected. Money is being spent on improving internet access, computers in schools and so on. Local business is beginning to embrace the internet and there is an increasing demand for .go domain names.

Using this background we will then move on to examine a number of scenarios regarding a change to the ccTLD manager. The idea is put a panel together map out some scenarios that might occur leading to a request for change of manager and discuss what should happen in each scenario.

It will not be about putting individuals 'on the spot.' Rather it will be about using an imaginary country to discuss some of the real issues that arise when a request is made and get opinions on what alternative solutions there may be. I'm also intending it to be FUN!37

After the above email was posted, there were vehement outcries against such a proposal. Those who had been appointed by Postel to administer virtual countries of foreign nations argued strongly that the issue was out of ICANN's scope.

Another legacy of the geopolitical situation was translated into the delegation process for Palestine. Palestine asked Postel to delegate its virtual country in early 1997, when Palestine was not internationally recognized as an independent state. At the time of the 1997 inquiry, .PS was on the reserved list. Postel refused to delegate.PS

37. ccTLD-discuss list, March 19, 2006 on the thread of Hypothetical Change of ccTLD manager. 
to Palestine. Instead, he proposed to delegate the second-level domain "palestine.int" based on Palestine's status as a Permanent Observer to the United Nations. In 1998, Palestine.int was delegated to Dr. Qadah, the supervisor-general of the Government Computer Center in Palestine, as the administrative contact, and Dr. Dolah, a resident of New York State, as the technical contact. Palestine.int was used in a limited way for a government-purposes third-level domain (such as gov.palestine.int).

In the summer of 1999, the United Nations Statistics Division notified the ISO 3166 Maintenance Agency that it included "Occupied Palestinian Territory" on the United Nations list of Standard Country and Area Codes for Statistical Use. In the fall of 1999, ISO announced that .PS was now on the ISO 3166-1 list. Dr. Qadah and Dr. Dolah asked for the .PS delegation in Oct. 1999. After IANA's evaluation and consultation, IANA confirmed that the former contacts for .Palestine.int could serve.PS.

In principle, as was confirmed with the.$P S$ delegation, IANA was supposed to base the delegation of virtual countries on the ISO 3166-1 list. But there were exceptions: Ascension Island .AC from the reserved list in December 1997, Guernsey .GG in August 1996, Jersey .JE in August 1996, and Isle of Man .IM in September 1996. Although Postel (IANA) refused to delegate .PS to Palestine because it was not on the ISO 3166-1 list in 1997, IANA delegated another reserved code from ISO 3166-1 list .$A C$ to a British businessman in 1997. Different rules for different actors. "During a brief period in 1996, Postel followed the policy of delegating virtual countries not only from the ISO 3166-1 list but also from the codes the ISO 3166 Maintenance Agency had reserved specifically for purposes of the United Postal Union. That policy proved unsatisfactory and was quickly abandoned in favor of strict adherence to the ISO 3166-1 list." 38

More than 50 virtual (island) countries are a third example of the legacy of global political economy. The virtual countries associated with islands sometimes do not have their own residents, or they only have a small number of residents, so their space was developed as globalized commercial spaces by the business sector, another nonstate actor as in the cases of.$T V$ or $. M D .^{39}$ This allows politically or economically

38. IANA Report on Request for Delegation of the .ps Top-Level Domain.

39. The combination of letters in Modova's code, .md was expected to appeal to doctors in the United States. The Moldovan administrator granted an American company the rights to license .md domains, hoping to raise revenue for Moldova's struggling economy. MaxMD licensed the right to market .md in more than 90 countries (though not in Moldova itself). The company's goal is to create a full-fledged online community of healthcare providers. .md currently has registered over 11,000 addresses, including individual physicians and practices, hospitals (including the Mayo Clinics at www.mayo.md), medical organizations (including the National Institutes of Health, which owns www.physician.md), and compa- 
powerful countries to have more virtual countries than other countries. Should they still be considered virtual (island) countries, or should they be considered only as global city-like virtual spaces on the Internet? The benefit of being recognized as virtual countries is that they could enjoy more independence in setting up their policies. These virtual (island) countries were categorized under generic TLDs in RFC 3071, "Reflections on the DNS, RFC 1591, and Categories of Domains" (Klensin, 2001). "Virtual countries operated as generic domains ought to be treated as generic domains. ICANN dispute resolution and name management policies and any special rules developed to protect the Internet public in multiple registrar or registry situations should reasonably apply."

Lastly, the openness of virtual countries is also related with the legacy of global political economy. Not only virtual island countries but also virtual countries that have formal relations with related governments have opened their cyberspace territory to everybody in the world, so there is no difference between them and generic top-level domains (gTLDs) like .COM. Such virtual countries have been filled with those who have commercial motivations in the space and therefore the space becomes extremely global and commercial. What made countries like Mexico, the United Kingdom, and China open their virtual countries to the world, while countries like Korea, Australia, and the United States restrict their virtual countries to people or entities under their jurisdiction? The decision to open their virtual countries could be related to some of the following factors. First, non-state actors made such decisions without formal consultation with the government. Second, countries like China and the United Kingdom have more than multiple virtual countries, so they are willing to explore their virtual country as a global space rather than national one. Third, the countries with a previous history of having been an empire are willing to become the center of global transactions. However, countries like the United States and Australia that have multiple virtual countries under their jurisdiction pay more attention to their security and identity and attempt to develop their virtual countries as national spaces.

According to the 2003 OECD report, 13 virtual countries ${ }^{40}$ have opened their spaces to the global community, and 17 virtual countries ${ }^{41}$ have kept them within their

nies, including Merck or Eli Lilly as well as Moldovan sites. "If the new medical domain really takes off, it could offer a new range of opportunities for communicating with physicians and patients. The experiment seems promising enough that pharma-marketers need to be aware of it - and perhaps start thinking about addresses they anticipate needing in the future" (OECD Report 2006. Source: Pharmaceutical Executives, Mar 2006, Vol. 26 Issue 3).

40. Austria, Belgium, Czech Republic, Denmark, Greece, Mexico, Netherlands, New Zealand, Poland, Portugal, Switzerland, Turkey and United Kingdom (OECD Report 2003).

41. Australia, Canada, Finland, France, Germany, Hungary, Iceland, Ireland, Italy, Japan, 
nationals and entities. According to the 2006 OECD report, three countries (Hungary, Spain, and Sweden) have joined to open their virtual countries to the global community. As a result, 16 virtual countries have opened their spaces to the global community, and fifteen virtual countries ${ }^{42}$ have kept them for their nationals. Some virtual countries have been intentionally developed as market-oriented spaces under loose government involvement. ${ }^{43}$ Even the virtual countries overseen by state actors, such as Australia .AU and Canada .CA, have encouraged introducing more market-oriented policies.

\section{Dilemma of Non-State Actors with Their New Coordinator, ICANN/USG}

The role of IANA became more controversial after the passing of its emperor, Jon Postel. According to NTIA's IANA Functions Statement of Work, "(IANA) coordinates the assignment of technical protocol parameters, performs administrative functions associated with root management, allocates Internet Numbering Resources and other services." Other services include registries and registrars for .ARPA and .INT. IANA's root management function is the most politically sensitive service (Mueller, 2002). According to IANA's processing steps, every change recommended by IANA needs to be "sent to US Department of Commerce for approval. They (DoC) review all root zone requests to make sure we (IANA) followed policy." It is later "sent to VeriSign to update the zone. They (VeriSign) run the 'A' root server, essentially the primary for the root." After DoC and VeriSign, IANA "updates the database." 44 This political sensitivity touches on a nation's sovereignty.

Another politically sensitive situation was generated by ICANN itself. When a virtual country requested IANA's database update on its contacts, ICANN saw it as a chance to ask the virtual country for a contract. If virtual countries were unwilling to engage in such a dialogue, the whole process was either slowed down or stopped. This often provoked some to argue that "the functions of the IANA should be separated from the ICANN or at least that the IANA functions should be provided to the operators of ccTLDs (virtual countries) even if the operator has not signed a contract with ICANN."45

Korea, Luxembourg, Norway, Slovak Republic, Spain, Sweden, and United States (OECD Report 2003).

42. .EU was introduced in 2005 and it has a policy to keep the space for EU nationals only.

43. E.g., Burundi.

44. Introducing IANA Root Management ccTLD Workshop, Dubai 2006.

45. Workshop on Member States' experiences with ccTLD Geneva, 3-4 March 2003 ccTLD Doc 59. 
Politically embedded IANA operations by ICANN in coordination with USG have made many administrators of virtual countries feel reluctant to pay for this portion of the ICANN budget. ${ }^{46}$ ICANN can extort fees from virtual countries for the services of IANA, which was procured for free from DoC. When ICANN began providing IANA services to the administrators of virtual countries, suddenly the cost of operating IANA became more than 7 million dollars, one third of the ICANN budget. In principle, ICANN's budget is covered by contributions from gTLD registries, RIRs, and ccTLD registries, each being responsible for one third of the total budget.

IANA's political sensitivity controversy led to the question of whether the virtual countries on the Internet could enjoy sovereignty while under the coordination of a single government. The concerns about the sovereignty of virtual countries were well addressed in von Arx and Hagen's (2002) article, "Sovereign Domains: A Declaration of Independence of ccTLDs (virtual countries) from Foreign Control." von Arx and Hagen observed that there were risks of losing virtual countries' sovereignty under the foreign control of the root. "The power of ICANN to threaten a ccTLD (virtual country) with potential redelegation or annihilation provides ICANN with a mechanism to ensure ccTLD (virtual country) compliance with ICANN policies and to force the adoption of ICANN-friendly contractual terms and conditions."

von Arx and Hagen listed the following threats to the sovereignty of a virtual country when the root is under foreign control. First, "ICANN can effectively decide the identity of registries (virtual countries). . . . An additional risk is that ICANN will impose terms on the registrars that are not in the national interest of the country associated with the ccTLD (virtual country). It could also extend its regulatory functions into areas pertaining to relations between registrars and registries, consumer complaints and mergers of registries, further extending its reach into the domestic affairs of foreign nations." These concerns about the regulation of registries (agencies for the virtual world) by ICANN may be legitimate in the case of developing countries whose governments are not competent enough to deal with their domestic matters-including their virtual countries - but not in developed countries whose governments can take actions on the virtual countries under their jurisdiction.

46. Workshop on Member States' Experiences with ccTLD Geneva, 3-4 March 2003 ccTLD Doc 28, Extension of contract between IANA and ICANN.

"We (Nominet) have attempted to persuade the management of ICANN to adopt a more lightweight approach, to concentrate their policy discussions on persuasive rather than binding agreements, to separate the funding aspects of policy-making and operations and only to do those minimum functions necessary to give a business efficacy to their technical coordination role. Regrettably, ICANN does not appear to have listened to our concerns." 
Second, "The technical control over the A root has enabled ICANN to embark on a program to enlarge rights exceeding those that formerly existed for names. . . . the United States trademark law is now, in certain cases, applicable to gTLD domain name registrations throughout the world. ... The United States interests may eventually push for United States trademark law to apply to ccTLDs (virtual countries) as well." Again, their concerns turned out to be irrelevant, at least for now. Some virtual countries, in consultation with their national legal systems, voluntarily adopted the Uniform Dispute Resolution Procedure (UDRP), which was originally invented for gTLD disputes. If they want to change the rules, virtual countries and their governments have the liberty to do so.

The third threat to the sovereignty of a virtual country that von Arx and Hagen identified is that "Control over the A root implies, that ICANN can force ccTLDs (virtual countries) to ensure that their registration data is accurate and current, and that ICANN has access to such information. In fact, ICANN's model ccTLD (virtual country) sponsoring agreement already provides that: $[t]$ he Sponsoring Organization shall ensure that the zone file and accurate and up-to-date registration data for the Delegated ccTLD (virtual country) is continuously available to ICANN, in a manner which ICANN may from time to time reasonably specify, for purposes of verifying and ensuring the operational stability of the Delegated ccTLD (virtual country) only." This is a serious threat to sovereignty, and therefore there are still many virtual countries, especially European virtual countries, reluctant to sign a contract with ICANN.

The fourth threat is the threat to national security. von Arx and Hagen quoted Bill Clinton: "In addition to 'traditional' weapons of mass destruction, new forms of Strategic Information Warfare (SIW) will be developed and perhaps used as a new form of offensive warfare. SIW involves cyber-attacks against major national command systems and military-related operating systems."47 von Arx and Hagen echoed that "both civilian and military infrastructure in many nations are becoming increasingly dependent on the existence of the Internet, the ability to disrupt an enemy's communication might be a strategic asset. From the point of view of military reasoning, cyberspace is a new battle space to which military principles apply on par with land, sea and aerospace." 48

According to the Chairman of the Joint Chiefs of Staff, "The full spectrum domi-

47. United States Commission on National Security/21st Century, New World Coming: American Security in the 21st Century, Supporting Research and Analysis 52 (1999) available at http://www.nssg.gov/NWR_A.pdf (Sept.15, 1999).

48. Froomkin, Michael "Wrong Turn in Cyberspace: using ICANN to Route Around the APA and the Constitutions", 50 Duke L.J. 17. 
nance implies that US forces are able to conduct prompt, sustained, and synchronized operations with combinations of forces tailored to specific situations and with access to and freedom to operate in all domains - space, sea, land, air, and information." 49 The Energy and Commerce Committee's letter to Secretary Donald Evans of DoC stated, "Finally, we want to strongly reiterate our support for continued Department of Commerce control over the so-called 'A-Root' server. We believe that any assumption of control over that asset by any outside entity would be contrary to the economic and national security interests of the United States." von Arx and Hagen raised the concern that "if the DNS is vital to the national security of the United States, then parity of reasoning suggests that it is vital to every other country as well. Therefore, the national security arguments that the United States military and governmental officials have advanced favoring U.S. control over the DNS apply equally well to the interests of other nations."

When the virtual countries became open to the citizens of each country in the late 1990s, the space started to build its rules under country code more strongly. As it was developed into an increasingly sovereign space in the globalized network on its own, it in turn drew the attention of governments wishing to ensure their footprint in such a space. Despite DoC's recommendation in the White Paper in 1998 that Internet resources should be managed by the private sector, many virtual countries have gone through legislation processes in their own countries, declaring that the final authority of the virtual country rests with each government instead of the virtual country manager appointed by Jon Postel and listed in the IANA database.

\section{Evolution of the Concept of Virtual Countries' Local Internet Community}

When virtual countries were considered experimental spaces, Jon Postel appointed not state actors but non-state actor network researchers and business people to administer the virtual countries. When this space evolved into a substantial "territory" where people "live," this situation created tensions between non-state actors and state actors over who controls the virtual country. Governments were surprised to learn that the authority in their virtual countries had been appointed by Jon Postel, an individual from the United States. That led to a series of debates, beginning in 1998, on delegation issues of virtual countries in ICANN. According to RFC 1591, ccTLD managers (those who manage the virtual countries) are "trustees of the (delegated) top-level domains for the nation." RFD 1591 also emphasized that managers of the virtual

49. Chairman of The Joint Chiefs of Staff, Joint Vision 2020, available at http://ww.dtic.mil/ jv2020/jv2020.doc (June 2000). 
countries "have a duty to serve the community."

The concept of community has evolved into the "local Internet community" 50 concept in ccTLD constituency Best Practice Guidelines for ccTLD Managers (February 2000, 1st Draft) and the "local community" concept in ccTLD Delegation and Administration Policies (March 2000 ICANN meeting in Cairo). According to the 2000 ccTLD constituency's guidelines, a Local Internet Community is "the Internet industry and users and the government and authorities of the state or territory with which ccTLD is associated. The definition of Local Internet Community may vary from one country/territory to another, and is essentially a matter for the community in a given country/territory to decide. The definition of the Local Internet Community should be documented, available for public inspection, and transparent to the local community."

Some governments were concerned that they had to delegate their sovereign power to non-state actors, leaving the government as one of the subjects in the space under the non-state actor's administration. On the other hand, governments also learned that the concept of local Internet community was promoted by ICANN to recognize nonstate actors as legitimate decision makers. As a compromise, governments described their own local Internet community as a multistakeholder-based one. According to the Review of Proposal for the Management of Nigeria's virtual country.$N G^{51}$ put forward by the Nigerian government, the local Internet community of Nigeria is composed of 22 parties of multistakeholders from government, business, and civil society. 52

The concept of local Internet community was well received by the non-state actor ccTLD community until the ccTLD community was strongly engaged in confrontation

50. This term has been confusingly used to support legitimacy of the delegated administrative contact of ccTLD. A local Internet community includes government as well as other communities in the national boundary. Therefore, this term was coined to refer to a national Internet community that is the counterpart of the global Internet community.

51. http://www.nigeriavillagesquare1.com/Articles/oyesanya/2004/12/nigeria-review-of-proposal-for.html.

52. Multi-stakeholder Local Internet Community Defined by Nigeria Government National Information Technology Development Agency, Nigerian Communications Commission, Internet Services Providers Association of Nigeria, Nigeria Internet Group, Computer Professionals Registration Council of Nigeria, Council for Registration of Engineers in Nigeria, Nigerian Universities Commission, Nigeria Society of Engineers, National Broadcasting Commission, Association of Telecommunications Companies, Federal Ministry of Science and Technology, Federal Ministry of Communications, Federal Ministry of Education, Federal Ministry of Information and National Orientation, The Presidency, Bankers Committee of Nigeria, Civil Society Organizations, Youth Groups, The Media, Nigerian Information Technology Professionals Association, and Representative of State Government. 
with the Government Advisory Committee (GAC)/ICANN. This concept is not widely used any more, especially since ICANN became more sensitive to the issue of national sovereignty on the Internet. ICANN, on the other hand, found that the concept was still useful in communicating with governments and ensuring governments' compliance with ICANN's rules as one of the actors of the local Internet community.

\section{Evolution of Virtual Countries' Policymakers}

In 1977, the Internet project funded by ARPA decided to create its own RFC-like series of technical notes, the Internet Experiment Notes or IENs. Jon Postel became the editor for the new IEN series as well as for the long-standing RFC series. Two hundred and four IENs were published between March 1977 and September 1982. After the IEN series, RFC became the single document series for all ARPAnet- and Internet-related documents. 53

After two years of Domain Name System (DNS) experience with both gTLDs and ccTLDs, RFC 1032, "Domain Administrators' Guide" (Stahl, 1987), 54 specified a domain name registration policy of (a) naming conventions; (b) a first-come, firstserved policy; and (c) whois, the database of registrants of domain names. All of the registration policies Stahl made are still respected today.

We are living with the legacy of the first generation of ccTLD policymakers. They were academic engineers and managed the ccTLD space around the world until very recently. This explains why ccTLD spaces have been administered very conservatively with strict rules and regulations until recently. The academic engineers were more interested in ensuring the system than in registering more domain names. The ccTLD space has been changed substantially by the second generation of ccTLD policymakers, with more focus on providing better service to their customers. We also observe more policymakers from governments as a third generation engaged in shaping ccTLD space.

\section{Evolution of Virtual Countries' Administrators}

These changes were presented by Geist (2004) through his survey study, supported by the International Telecommunications Union, of more than 60 virtual countries.

53. http://www.rfc-editor.org/RFCoverview.html.

54. "This memo should be used in conjunction with RFC 920, which is official policy statement of the Internet Activities Board (IAB) and the Defense Advanced Research Projects Agency (DARPA)." 
However, his outcome was not well received, because of the political objections of the non-state-actor administrators of virtual countries. Most virtual countries started as individual research projects without government regulation. These have evolved into either academic research operations or private sector operations under government supervision, public sector operations under government regulation, or independent private sector operations. The evolution of administrators of virtual countries has occurred in response to changes in the dynamics of virtual countries and later changes in the regulatory systems of virtual countries. The first evolutionary process of administrators of virtual countries was the result of responding to increasing demands to own real estate in virtual countries. Many pioneering virtual countries, including the United Kingdom .UK, and Germany .DE, experienced their institutional changes in the mid1990s. The second evolution process was the result of responding to governments' increasing awareness of their virtual countries as critical national strategic resources.

An overview of the types of administrators of virtual countries (as of 2007) will illustrate to what extent governments are involved in their virtual countries' governance mechanisms. The types of administrators of virtual countries were identified through the IANA ccTLD database and they were divided into the following four categories. First, 54 virtual countries are still associated with academic networks, and most of them have very loose connections with their governments. However, as funding sources, governments play the role of supervisor of their academic projects. Second, 53 virtual countries are operated by the private sector, either under governmental regulation or without any form of government involvement. Third, 58 virtual countries are regulated either by national governments directly or by national government agencies. Fourth, 20 virtual countries have institutionalized multistakeholder governance. The governance nature of 55 virtual countries has not been clearly identified as of 2007 . Three virtual countries (Antarctica . $A Q$, Aruba . $A W$, and Barbados . $\mathrm{BB}$ ) have been run by an individual without connections with their corresponding governments.

\section{CONCLUSIONS}

From 1998 until the present, ICANN, which was founded on the principle of private sector leadership of virtual countries, has delegated virtual countries to state actors instead of non-state actors, except in the case of Serbia. This article did not cover in detail this growing phenomenon of ICANN's redelegation of virtual countries

55. The re-delegation cases will be covered by my upcoming article ("Hegemony of the Regime: Non-State Actors vs State Actors). 
from non-state actors to state actors. ${ }^{55}$ As a result of ICANN's self-contradicting actions, the administration of virtual countries has gradually moved from the hands of non-state actors to those of state actors. ICANN's delegation behavior confirmed the role of state actors in administering the virtual countries and made non-state actors appointed by Postel, their own emperor, feel powerless to react to political decisions under a different regime.

Despite the explicit blessing of the governments of the EU, United Kingdom, Australia, Canada, and Japan, ICANN is still the subject of doubts about its legitimacy as a global regime. ICANN's delegation of ccTLDs to state actors can be explained by its own struggle in securing legitimacy as a global regime. Those who have questioned ICANN's legitimacy-including the governments of Brazil, Russia, India, China (BRIC), and Arab countries during the UN World Summit on the Information Society (WSIS) in 2003 and in 2005-are not still convinced by the U.S. government's declaration that ICANN is doing fine.

The destiny of ICANN as a global entity still depends on its hegemonic power, the U.S. government. ICANN has intentionally made its strategic decisions to embrace state actors, even though it was identified as a private sector regime by its creator, the U.S. government. To satisfy both its hegemonic power and state actors who have the ability to set up a state-actor oriented coordination mechanism through the UN, ICANN has no choice but to delegate the rights to administer virtual countries to state actors instead of non-state actors.

For the past 10 years, from 1998 to 2008, the ICANN experiment has been a mutual learning process. Non-state-actor administrators have learned they have to coordinate with their corresponding state actors as well as their emperor's successor, ICANN, to keep their status as administrators. Those who failed to recognize the authority of state actors lost their status as administrators, especially when state actors decided to regain the power over virtual countries. State actors have also learned that the administration of networked virtual countries is quite different from administering territorial countries whose boundaries are clear. Those who failed to understand the networked nature of virtual countries fell behind in developing their virtual countries as both secured and attractive global or national markets.

ICANN is also learning very slowly to be more sensitive to ongoing threats expressed by the nonparticipant state actors of China, Russia, and Arab countries during the UN Internet Governance Forum (IGF). ICANN is becoming more responsive to the concerns raised by the dilemma of non-state-actor administrators of virtual countries under ICANN/USG coordination, and it tries to coordinate more issues at the joint ccNSO and Government Advisory Committee (GAC) meetings. It recognizes the contradiction of state actors having advisory status and observing non-state actors' 
decision making processes. ICANN has consulted with the GAC more and more according to the modified bylaws in 2002.56

This dynamic has led to the evolution from non-state actor leadership of local Internet communities to state-actor leadership, the evolution of non-state-actor ICANN policymakers to state-actor policymakers, and the evolution from non-stateactor administrators of virtual countries to state-actor administrators.

Will this self-contradicting behavior lead to ICANN's transformation from a nonstate-actor decision-making entity to a state-actor decision-making entity? It will depend on the influence of hegemonic power: If the U.S. government is able to firmly maintain its hegemonic power, ICANN will keep its status as a private sector regime. If the U.S. government should at some point fail to maintain its hegemonic power, ICANN's private-sector orientation may be challenged by anti-hegemonic power interests.

This article focused on explaining why we face contradictory principles in administering virtual countries. Postel's non-state-actor legacy in the early days contributed to creating a non-state actor oriented global regime. However, the insecure global regime built on the principle of private sector leadership, continuous challenges against the warmongering hegemonic power in the UN IGF, and increasing recognition by the WSIS and state actors of virtual countries as strategic national resources will lead to more state-actor administrators of virtual countries. Such a situation will be contradictory to the ICANN's principle of private sector leadership.

\section{REFERENCE}

Arx Kim G. v. \& Hagen, Gregory R. 2002 'Sovereign Domains: A Declaration of Independence of ccTLDs from Foreign Control' RICH. J.L. \& Tech.

Geist, Michael 2004 'Governments and Country-Code Top Level Domains: A Global Survey' version 2.0.

Haufler, Virginia 1993 'Crossing the Boundary between Public and Private: Interna-

56. ICANN Bylaws Section 2. SPECIFIC ADVISORY COMMITTEES

j. "The advice of the Governmental Advisory Committee on public policy matters shall be duly taken into account, both in the formulation and adoption of policies. In the event that the ICANN Board determines to take an action that is not consistent with the Governmental Advisory Committee advice, it shall so inform the Committee and state the reasons why it decided not to follow that advice. The Governmental Advisory Committee and the ICANN Board will then try, in good faith and in a timely and efficient manner, to find a mutually acceptable solution." 
tional Regimes and Non-State Actors' Rittberger, Volker (Ed.) 1993 Regime Theory and International Relations. Clarendon Press Oxford.

Mueller, Milton 2002 Ruling the Root. MIT Press.

Russel, Andrew 2006 'Rough Consensus and Running Code and the Internet-OSI Standards War' IEEE Annual of the History of Computing.

\section{Hearings}

Serial No. 105-113 Hearings before the subcommittee on telecommunications, trade, and consumer protection of the Committee on Commerce House of Representatives One Hundred Fifth Congress Second Session June 10, 1998. The Future of the Domain Name System.

Serial No. 107-4 Hearing before the subcommittee on telecommunications and the Internet of the Committee on Energy and Commerce House of Representatives One Hundred Seventh Congress First Session February 8, 2001. Is ICANN's New Generation of Internet Domain Name Selection Process Thwarting Competition?

S. HRG. 107-1100 Hearing before the subcommittee on communications of the Committee on Commerce, Science, and Transportation United States senate One Hundred Seventh Congress First Session February 14, 2001. ICANN Governance.

Serial No 8. Hearing before the subcommittee on courts, the Internet, and intellectual property of the Committee on Judiciary House of Representatives One Hundred Seventh Congress First Session March 22, 2001. ICANN, new gTLDs, and The Protection of Intellectual Property.

Serial No. 23 Hearing before the subcommittee on courts, the Internet, and intellectual property of the Committee on the Judiciary House of Representatives One Hundred Seventh Congress First Session July 12, 2001. Whois Database: Privacy and Intellectual Property Issues.

\section{Request for Comments}

Request for Comments 799 Internet Name Domains Mills, D.L. COMSAT Laboratories, Sept. 1981.

Request for Comments 819 The Domain Naming Convention for Internet User Applications Su, Zaw-Sing SRI and Postel, Jon ISI Aug. 1982.

Request for Comments 830 A Distributed System for Internet Name Service Su, ZawSing SRI Oct. 1982.

Request for Comments 881 The Domain Names Plan and Schedule Postel, J. ISI Nov. 1983.

Request for Comments 882 Domain Names - Concepts and Facilities Mockapetris, P. ISI Nov. 1983. 
Request for Comments 883 Domain Names - Implementation and Specification

Mokapetris, P. ISI 1983.

Request for Comments 897 Domain Name System Implementation Schedule Postel, J. ISI Feb. 1984.

Request for Comments 920 Domain Requirements Postel, J. and Reynolds, J. ISI Oct, 1984.

Request for Comments 921 Domain Name System Implementation Schedule Revised Postel, J. ISI Oct. 1984.

Request for Comments 973 Domain System Changes and Observations Mockapetris, Paul ISI Jan. 1986.

Request for Comments 1032 Domain Administrators Guide Stahl, M. SRI International Nov. 1987.

Request for Comments 1033 Domain Administrators Operation Guide Lotter, M. SRI International Nov. 1987.

Request for Comments 1034 Domain Names - Concepts and Facilities Mockapetris, P. Nov. 1987.

Request for Comments 1035 Domain Names - Implementation and Specification Mockapetris, P. ISI Nov. 1987.

Request for Comments 1480 The US Domain Cooper, A. and Postel, J. June 1993.

Request for Comments 1462 FYI on "What is the Internet?" FYI 20 Krol, E. University of Illinois and Hoffman, E. Merit Network, Inc. May 1993.

Request for Comments 1591 Domain Name System Structure and Delegation Informational Postel, J. ISI March 1994.

\section{IANA Reports}

Report on Delegation of the eu Top-Level Domain (http://www.iana.org/reports/eu-report-05aug05.pdf).

Report on Redelegation of the .fk Top-Level Domain (http://www.iana.org/reports/fk-report-05aug05.pdf).

Report on Redelegation of the .za Top-Level Domain (November 2004)

(http://www.iana.org/reports/za-report-05aug05.pdf).

Report on Redelegation of the .ng Top-Level Domain (10 June 2004)

(http://www.iana.org/reports/ng-report-10jun04.htm).

Report on Redelegation of the .ps Top-Level Domain (April 2004)

(http://www.iana.org/reports/ps-report-21jun04.htm).

Request for Redelegation of .md Top-Level Domain (22 October 2003)

(http://www.iana.org/reports/md-report-22oct03.htm).

Report on Deletion of the .zr Top-Level Domain (20 June 2001) 
(http://www.iana.org/reports/zr-report-20jun01.htm).

Report on Request for Delegation of the .ps Top-Level Domain (22 March 2000)

(http://www.iana.org/reports/ps-report-22mar00.htm).

Report on Request for Redelegation of the .pn Top-Level Domain (11 February 2000)

(http://www.iana.org/reports/pn-report-11feb00.htm).

\section{OECD Reports}

Evolution in the Management of Country Code Top-Level Domain Names (ccTLDs) 17-Nov-2006.

OECD Input to the United Nations Working Group on Internet Governance (WGIG) 2005.

Generic Top Level Domain Names: Market Development and Allocation Issues 2003.

Comparing Domain Name Administration in OECD Countries 2003. 